\title{
DESIGUALDADES EDUCATIVAS ESTRUTURAIS NO BRASIL: ENTRE ESTADO, PRIVATIZAÇÃO E DESCENTRALIZAÇÃO
}

\author{
A. J. AKKARI*
}

\begin{abstract}
RESUMO: No Brasil, mais que em outros países do Sul, a escola constitui um produto social desigualmente distribuído. Seu acesso é modulado não apenas por múltiplos padrões distintivos (categoria socioeconômica, sexo, etnicidade, local de residência...), como também pelo tipo de rede escolar freqüentado (pública, particular). Este artigo analisa a constituição histórica e progressiva de uma escolarização em várias velocidades. O discurso político republicano, que insiste sobre a função homogeneizadora e igualitária da escola que socializa em comum e fabrica cidadãos iguais, foi se esvaziando progressivamente de sua substância. A heterogeneidade provocada pela atual fragmentação do sistema escolar brasileiro em várias redes reproduz, acentuando-as, as desigualdades sociais e compromete de modo durável o desenvolvimento econômico e social desse país.
\end{abstract}

Palavras-chave: Brasil, desigualdade sociais, ensino público, ensino particular.

\section{Introdução}

A comparação entre diferentes sistemas educativos levou muitos especialistas a postular a existência de um modelo universal de educação formal. Esse modelo foi experimentado pelos países ocidentais na segunda metade do século XIX e parece aplicar-se a outras regiões do globo. Os sistemas educativos dos países em desenvolvimento podem, portanto, ser assimilados a uma "fotocópia" defasada no tempo e de uma qualidade reduzida em relação ao modelo ocidental original.

\footnotetext{
* Universidade de Friburgo, Departamento de Ciências da Educação.
} 
Neste texto, queremos mitigar essa tese ao postular a constituição progressiva, no Brasil, de um sistema educativo fragmentado, compreendendo várias redes de velocidades diversas. Esse sistema mal se compara ao modelo ocidental. O caso brasileiro nos parece interessante por vários motivos. Primeiro, o Brasil é, por sua população, seu território e seu desenvolvimento econômico o maior país da América Latina. Segundo, a importância dos trabalhos brasileiros realizados sobre esse tema nos dá um acesso direto aos dados e análises locais. Finalmente, durante esses últimos cinco anos, visitas regulares no local nos permitiram verificar a leitura particular da situação educativa brasileira que tentamos desenvolver.

\section{Constituição histórica das redes}

Desde o começo do século passado, o desenvolvimento do sistema educativo brasileiro vem sendo marcado por relações conflitantes entre diferentes grupos sociais. Numa pesquisa histórica sobre a penetração protestante norte-americana no Brasil, Mesquida (1994) explicou como as elites intelectuais e políticas da região do Sudeste (maçons, republicanos, anticlericais, positivistas) sustentaram a igreja metodista na sua tentativa de instalar um ensino alternativo ao fornecido pelas escolas católicas e públicas, consideradas como passadistas, rígidas e pouco propensas a impulsionar o desenvolvimento econômico.

Podemos distinguir quatro períodos principais na história das lutas em prol da escola pública no Brasil. O primeiro (1934-1962) é marcado, nos anos 30 , pela discussão entre católicos e leigos quanto às orientações gerais da política educativa no país (Libaneo, 1985). Nos anos 50 e 60, o debate articulou-se em torno do conflito entre os defensores da escola particular e os da escola pública. Os primeiros, agrupados em torno da igreja católica, defendiam uma concepção religiosa e humanista do ensino; reclamavam até um financiamento público para a educação particular, de modo a garantir a "liberdade de escolha" dos pais. Os segundos, animados por movimentos progressistas e leigos, estimavam que apenas a escola pública estaria apta a garantir as mesmas chances educativas para todos os cidadãos brasileiros.

No plano pedagógico, esse primeiro período corresponde à introdução do pensamento pedagógico liberal no Brasil, principalmente por meio do engajamento dos pedagogos liberais em favor de uma melhor resposta à demanda social crescente por educação. Esse movimento culminou com o lançamento, em 1932, do manifesto dos pioneiros da escola nova, o qual 
preconizava uma universalização do ensino pelo desenvolvimento de um sistema de educação público. Esse documento considerava o ensino como uma função eminentemente social e pública (Azevedo et al., 1932). Da mesma forma, cabe assinalar a influência preponderante, no plano pedagógico, da Escola Nova com a contribuição central de Dewey.

O primeiro período acabou com a promulgação, em 1962, pelo Congresso brasileiro, de uma legislação completa sobre a educação (Lei de Diretrizes e Bases). Apesar de reforçar a escola pública no plano legislativo depois desse primeiro período, essa lei não constituiu um avanço sensível na construção do sistema público de educação. As comunidades desfavorecidas e as populações rurais permaneceram afastadas da escolarização maciça.

O segundo período, muito breve, corresponde ao surgimento do movimento de educação popular que se desenvolveu entre 1962 e 1964, graças, em particular, ao trabalho pioneiro do movimento de educação básica (MEB) e à atuação do pedagogo Paulo Freire. O debate deslocou-se, na época, do campo escolar para o da alfabetização de adultos e da educação popular num contexto político marcado por múltiplas lutas sociais.

O terceiro período teve início em 1964 com o advento do regime militar, que interrompeu brutalmente as expectativas suscitadas no país pelas campanhas de alfabetização popular. Esse regime tentou implementar uma política educativa tecnicista, centrada nos conceitos de racionalidade, eficiência e produtividade. Essa orientação, inspirada principalmente pelos acordos entre o Ministério da Educação e a Agência Americana de Ajuda ao Desenvolvimento (US-AID), foi combatida pela maioria dos educadores brasileiros, que não hesitaram em recusar o caráter autoritário do regime e de sua proposta pedagógica (Saviani, 1992).

O quarto período começa no início dos anos 80 com o retorno progressivo à democracia. $O$ debate girou, na época, em torno da democratização do ensino e da permanência das crianças desfavorecidas na escola. Várias medidas legislativas em prol da escola pública foram votadas, como a Nova Lei de Diretrizes e Bases da Educação Nacional, em 1996.

Esse sobrevôo rápido pelas condições históricas da constituição do sistema educativo brasileiro revela os principais debates ideológicos contemporâneos no país. Quase monopólio das ordens eclesiásticas nos seus primórdios, a educação formal foi progressivamente organizada pelo Estado imperial e, em seguida, pela república, para acompanhar o desenvolvimento econômico e a modernização. Entretanto, o Estado bra- 
sileiro nunca quis ou pôde controlar o conjunto do processo de escolarização de massa ao longo do século $X X$. O ensino particular constituiuse progressivamente como a única opção para os filhos da elite social. Apesar de uma legislação e de um discurso político onipresentes, a rede pública padece de numerosas fraquezas qualitativas e quantitativas. $O$ resultado atual é um sistema educativo fragmentado, organizado em redes disparates, dificilmente comparáveis entre si. Na seção seguinte, tentaremos descrever essas múltiplas redes.

\section{Características do sistema educativo brasileiro}

Do ponto de vista organizacional (Cf. Anexo I) e quantitativo, o sistema educativo brasileiro progrediu muito nessas últimas décadas. Um aumento sensível das taxas de escolarização em todos os níveis de ensino (inclusive pré-escolar) e uma baixa constante das taxas de analfabetismo podem ser claramente verificados. Assim, este último baixou de $39,5 \% \mathrm{em}$ 1960 para 20,1\% em 1991 (Guimarães, 1998). No plano quantitativo e global, a situação educativa brasileira compara-se à que prevalece em outros países em desenvolvimento, mesmo se o Brasil tende a ter melhores resultados no plano econômico. De fato, na classificação internacional da precariedade dos sistemas educativos nos países em desenvolvimento, o Brasil está 16 lugares abaixo de sua posição em função do PIB (Watkins, 1999).

A estrutura do ensino público brasileiro começa com a constituição de 1824, que reconhecia o direito de todo cidadão a uma educação primária. Em 1930, criou-se um ministério da educação. A seguir, a lei de diretriz da educação de 1962 instituiu três tipos de escolas públicas (federais, estaduais e municipais). A constituição de 1988 estabeleceu a convivência das redes pública e particular. Para a rede particular, uma distinção foi estabelecida entre instituições com e sem fins lucrativos (escolas comunitárias, filantrópicas e confessionais).

Parece-nos ser a dualidade ensino público/ensino particular a grade de leitura apropriada para analisar o sistema educativo atual no Brasil. A rede pública acolhe a maioria dos alunos, ao passo que a rede particular, elitista, é freqüentada exclusivamente pelas classes dominantes. Em 1996, o ensino público fundamental acolheu 29,4 milhões de alunos ( $88 \%$ do total de alunos), ao passo que o ensino particular recebeu apenas 3,7 milhões. No que diz respeito ao ensino médio, os setores público e particular acolheram, em 1996, respectivamente $79,5 \%$ e $20,5 \%$ dos alunos (INEP, 1996). 


\section{Tabela I}

\section{As redes pública, particular e comunitária de ensino no Brasil}

\begin{tabular}{|c|c|c|c|}
\hline Rede pública & Origem & Público & Características \\
\hline - Escolas Federais & $\begin{array}{l}\text { - Escolas de aplicação } \\
\text { pedagógica vinculadas a } \\
\text { universidades ou empresas } \\
\text { públicas. } \\
\text { - Escolas federais técnicas } \\
\text { superiores. }\end{array}$ & $\begin{array}{l}\text { - Alunos oriundos das } \\
\text { classes altas e médias. }\end{array}$ & $\begin{array}{l}\text { - Muito pouco } \\
\text { numerosas, essas } \\
\text { escolas organizam } \\
\text { concursos de ingresso } \\
\text { muito seletivos para as } \\
\text { poucas vagas } \\
\text { disponíveis. }\end{array}$ \\
\hline - Escolas estaduais & $\begin{array}{l}\text { - Escolas administradas } \\
\text { pelos Estados }\end{array}$ & $\begin{array}{l}\text { - Alunos oriundos das } \\
\text { classes médias e } \\
\text { desfavorecidas. }\end{array}$ & $\begin{array}{l}\text { - A situação dessas } \\
\text { escolas depende do } \\
\text { desenvolvimento } \\
\text { econômico do Estado, } \\
\text { com um contraste } \\
\text { marcado entres os } \\
\text { estados desenvolvidos } \\
\text { do Sul e do Sudeste e os } \\
\text { do Nordeste, } \\
\text { essencialmente rurais. } \\
\end{array}$ \\
\hline $\begin{array}{l}\text { - Escolas } \\
\text { Municipais }\end{array}$ & $\begin{array}{l}\text { - Escolas administradas } \\
\text { pelas municipalidades. }\end{array}$ & $\begin{array}{l}\text { - Alunos oriundos das } \\
\text { classes desfavorecidas. }\end{array}$ & $\begin{array}{l}\text { - Essas escolas são } \\
\text { numerosas e têm taxas } \\
\text { de repetência e } \\
\text { abandono muito altas. }\end{array}$ \\
\hline \multicolumn{4}{|l|}{ Rede particular } \\
\hline $\begin{array}{l}\text { - Escolas } \\
\text { internacionais }\end{array}$ & $\begin{array}{l}\text { - Escolas localizadas } \\
\text { essencialmente em São } \\
\text { Paulo e no Rio de Janeiro. }\end{array}$ & $\begin{array}{l}\text { - Alunos oriundos das } \\
\text { classes altas } \\
\text { (profissionais } \\
\text { estrangeiros). }\end{array}$ & $\begin{array}{l}\text { - Essas escolas, pouco } \\
\text { numerosas, têm boa } \\
\text { reputação no setor da } \\
\text { educação bilingüe } \\
\text { (principalmente } \\
\text { português-inglês). } \\
\end{array}$ \\
\hline $\begin{array}{l}\text { - Escolas } \\
\text { "tradicionais" } \\
\text { confessionais } \\
\text { (católicas, } \\
\text { protestantes) }\end{array}$ & \begin{tabular}{|l|} 
- Na origem, essas escolas \\
eram vinculadas às \\
poderosas congregações \\
católicas (jesuítas, maristas, \\
dominicanas) ou protestantes \\
(metodistas, evangélicas, \\
entre outros). \\
- Essas escolas vêm se \\
desenvolvendo fortemente \\
esses últimos anos.
\end{tabular} & $\begin{array}{l}\text { - Alunos oriundos das } \\
\text { classes altas e médias- } \\
\text { altas. }\end{array}$ & $\begin{array}{l}\text { - Seu número está } \\
\text { aumentando } \\
\text { constantemente. } \\
\text { - O ensino religioso está } \\
\text { perdendo espaço à } \\
\text { medida que sua base } \\
\text { confessional de } \\
\text { recrutamento se amplia. }\end{array}$ \\
\hline
\end{tabular}

Fonte: Autor

A Tabela I mostra a existência de pelo menos três redes de ensino primário e secundário, representadas por diferentes tipos de escolas. Os serviços educativos (quantidade e qualidade) dessas redes variam muito dentro de um mesmo estado, assim como entre estados. Nas regiões rurais e afastadas dos centros, a oferta limita-se mais freqüentemente 
às escolas municipais e estaduais, sendo o ensino particular muito pouco desenvolvido. As famílias abastadas dessas regiões não hesitam em escolarizar seus filhos a dezenas de quilômetros de seus domicílios.

As disparidades entre estados também são flagrantes. O Nordeste dispõe de uma rede pública particularmente degradada. O número de docentes leigos (sem formação pedagógica) é um dos indicadores que reflete essa precariedade.

\section{Tabela II}

Professores leigos nas escolas primárias no Norte e Nordeste

\begin{tabular}{|l|l|l|l|}
\hline Estados & Número de professores & $\begin{array}{l}\text { \% de professores com } \\
\text { primário incompleto }\end{array}$ & $\begin{array}{l}\text { \% de professores com o } \\
\text { ensino médio incompleto }\end{array}$ \\
\hline Rondônia & 8104 & 12.1 & 31 \\
\hline Pará & 36.365 & 11,7 & 29,5 \\
\hline Tocantins & 8.463 & 17,2 & 31,1 \\
\hline Maranhão & 39.909 & 18,7 & 29,7 \\
\hline Piauí & 22.773 & 16,6 & 27,1 \\
\hline Ceará & 44.048 & 10,8 & 24,5 \\
\hline Bahia & 77.278 & 10,1 & 19,9 \\
\hline Sudeste & $\mathbf{2 6 7 . 7 1 8}$ & $\mathbf{0 , 6}$ & $\mathbf{1 , 1}$ \\
\hline Sul & $\mathbf{1 1 3 . 1 6 2}$ & $\mathbf{0 , 9}$ & $\mathbf{4 , 2}$ \\
\hline Brasil & $\mathbf{7 9 8 . 9 4 7}$ & $\mathbf{5 , 5}$ & $\mathbf{1 1 , 9}$ \\
\hline
\end{tabular}

O Nordeste brasileiro constitui a maior concentração de pobreza na América Latina. Mais da metade das crianças nas zonas rurais do Nordeste recebem menos de 4 anos de escolaridade e um quarto da população nunca foi escolarizado (Watkins, 1999).

Cabe também notar que essas redes são dinâmicas e não estáticas. A qualidade da rede pública depende da política educativa desenvolvida no plano municipal, estadual e federal. Assim, a situação da rede pública da cidade de São Paulo melhorou ligeiramente com a administração escolar de Paulo Freire (1991). No entanto, em razão do interesse pedagógico tardio de Freire para a educação formal e da brevidade de sua passagem como secretário municipal de educação, ele não conseguiu exercer uma influência duradoura sobre a estrutura do sistema escolar dessa cidade.

A situação da rede particular depende dos incentivos fiscais dos poderes públicos e do grau de controle ao qual está submetido. A constituição de 1988 limitou, teoricamente, o repasse de recursos públicos para o ensino privado. Entretanto, importantes repasses indiretos ainda existem, especi- 
ficamente por meio da compra maciça, pelas escolas públicas, de manuais escolares junto de algumas grandes editoras privadas (Akkari, 1999).

Existe também uma possibilidade de circulação dos alunos entre as diferentes redes. Um mesmo aluno pode sair de uma rede e entrar em outra. Entretanto, não se trata de um "mercado concorrencial", uma vez que cada rede tem seu público ou seus consumidores próprios.

Neste ponto, as estratégias familiares são múltiplas. As famílias das classes médias altas às vezes mandam seus filhos numa escola primária pública, mas os transferem para as redes particulares no secundário, principalmente em virtude da perspectiva do vestibular. Da mesma forma, certas famílias das classes médias baixas podem transferir seus filhos das pequenas escolas particulares para as escolas públicas quando os custos de escolaridade aumentam demais ou suas situações econômicas se degradam sensivelmente, como é o caso atualmente na região industrial de São Paulo.

Contudo, é preciso enfatizar que a mobilidade entre as redes não é possível para todos e que ela é estreitamente vinculada ao poder de compra. As classes populares têm uma única escolha: a das escolas públicas municipais ou estaduais (que nem sempre existem nas zonas rurais). As crianças são, às vezes, obrigadas a sair do sistema educativo para inserir-se rapidamente no tecido produtivo e contribuir à sobrevivência econômica das famílias. Em 1990, 11\% das crianças entre 10 e 14 anos trabalhavam no Brasil (32\% no meio rural) (Saboia, 1996).

O dinamismo e a flexibilidade da rede secundária particular também merecem ser ressaltados. Assim, podemos constatar, de uns quinze anos para cá, a expansão vertical das escolas particulares secundárias, que se transformaram primeiro em faculdades (ministrando alguns cursos universitários) e depois em universidades, para responder a uma demanda crescente de ensino superior. Demanda sustentada pela luta por vagas ocasionada pelo vestibular.

Acrescentaremos que uma recente pesquisa nacional (Tabelas III e IV) mostra claramente a consolidação da estrutura do sistema educativo brasileiro em redes de várias velocidades. As disparidades entre regiões em matéria de aquisição dos alunos não podem ser negadas. Entre todas as regiões do país, os alunos das escolas urbanas têm melhores desempenhos em matemáticas que os que freqüentam escolas rurais. A maior diferença ( -35 pontos) está entre as escolas urbanas do Sudeste e as escolas rurais do Nordeste. O desempenho dos alunos em função do tipo de escola mostra diferenças ainda mais marcantes, 
principalmente entre as escolas municipais e particulares, que variam entre 48 e 56 pontos, sempre em favor das escolas particulares.

\section{Tabela III}

Resultado médio em matemática dos alunos de $3^{\underline{a}}$ série por região

\begin{tabular}{|l|l|l|}
\hline & Urbano & Rural \\
\hline Brasil & 189 & 167 \\
\hline Norte & 169 & - \\
\hline Nordeste & 178 & 161 \\
\hline Sudeste & 196 & 171 \\
\hline Sul & 195 & 181 \\
\hline Centro-Oeste & 186 & 165 \\
\hline
\end{tabular}

Fonte: Gomes de Sá Pestana et al. (1999).

\section{Tabela IV}

Resultado médio em matemática dos alunos de $3^{\underline{a}}$ série por tipo de escola

\begin{tabular}{|l|l|l|l|}
\hline & Escolas estaduais & Escolas municipais & Escolas particulares \\
\hline Brasil & 183 & 177 & 230 \\
\hline Norte & 167 & 163 & 213 \\
\hline Nordeste & 170 & 164 & 220 \\
\hline Sudeste & 191 & 184 & 238 \\
\hline Sul & 192 & 188 & 236 \\
\hline Centro-Oeste & 180 & 177 & 231 \\
\hline
\end{tabular}

Fonte: Gomes de Sá Pestana et al. (1999).

Os salários dos docentes são outro indício da disparidade entre as redes. Com exceção das escolas federais, pouco numerosas, os salários dos docentes da rede pública são nitidamente inferiores aos da rede privada. A diferença mais substancial está entre as escolas municipais do Nordeste e as escolas particulares do Sudeste. Os docentes, nestas últimas, ganham 5 vezes mais que os que trabalham nas primeiras (Tabela $V$ ). Esta diferença é na verdade subestimada, na medida em 
que os docentes das escolas particulares se beneficiam também de descontos substanciais nos custos de escolaridade de seus filhos.

\section{Tabela V}

Salário médio em $\mathrm{R} \$$ dos docentes do primário por região e dependência administrativa

\begin{tabular}{|l|l|l|l|l|l|}
\hline & $\begin{array}{l}\text { Total das } \\
\text { escolas }\end{array}$ & $\begin{array}{l}\text { Escolas } \\
\text { federais }\end{array}$ & $\begin{array}{l}\text { Escolas } \\
\text { estaduais }\end{array}$ & $\begin{array}{l}\text { Escolas } \\
\text { municipais }\end{array}$ & $\begin{array}{l}\text { Escolas } \\
\text { particulares }\end{array}$ \\
\hline Brasil & 420,10 & $1.103,30$ & 515,50 & 292,70 & 595,30 \\
\hline Norte & 365,80 & $1.296,40$ & 456,70 & 229,00 & 529,20 \\
\hline Nordeste & 222,00 & 438,10 & 344,70 & 155,20 & 288,10 \\
\hline Sudeste & 617,70 & $1.346,50$ & 616,20 & 545,50 & 782,70 \\
\hline Sul & 464,20 & 978,20 & 499,40 & 405,80 & 681,20 \\
\hline Centro-Oeste & 456,40 & $1.135,90$ & 451,40 & 315,30 & 562,50 \\
\hline
\end{tabular}

Fonte: Guimarães (1998).

As despesas por aluno podem também dar um indício da diferença de qualidade entre as redes pública e particular. As mensalidades pagas pelas famílias para cada criança freqüentando o ensino particular são, em média, amplamente superiores às despesas públicas anuais por aluno do ensino público.

Em 1997, da Silva (1998) observava que o custo mensal médio por menor internado numa instituição da Febem é de $R \$ 1.177,00$, ou seja, 24 vezes o que se gasta por aluno escolarizado na rede estadual de São Paulo. O descompromisso do Estado para com a educação espelha-se no fato de que se gasta muito mais para manter jovens num sistema carcerário absurdo do que para preparar a inserção socioeconômica dos alunos da rede pública. Simões Bueno (1996) ressalta que

O descompromisso do Estado foi adotado como uma verdadeira filosofia de governo. A ideologia de um mínimo de Estado substituiu-se às políticas anteriores de expansão do ensino secundário no território do Estado de São Paulo. Essa evolução constitui uma contradição flagrante com os dispositivos legislativos atuais que tendem a incluir o ensino secundário na educação básica. (p. 75)

A estruturação do primário e do secundário em redes particular e pública determina o público do ensino superior. De fato, em razão da dificuldade 
do vestibular para as universidades públicas, é praticamente impossível nelas encontrar estudantes que tenham freqüentado o ensino público no primário e no secundário. Elas são freqüentadas, quase exclusivamente, por alunos oriundos do ensino secundário particular. Os cursos mais concorridos nas universidades públicas são freqüentados por $80 \%$ de alunos que passaram por escolas particulares. Essa percentagem baixa para $40 \%$ nas disciplinas menos concorridas. No entanto, os alunos que terminam o ensino médio público são três vezes mais numerosos do que os que terminam o ensino secundário particular. No Vestibular para as faculdades públicas de medicina, um aluno oriundo do ensino particular tem uma chance em 9 de ser admitido, ao passo que quem vem do público tem uma chance em 104 (Lima, 1999).

É no mínimo estranho que o ensino só se torne "público" e "gratuito" quando todos os alunos desfavorecidos foram eliminados. O Ministério Federal da Educação gasta $60 \%$ de seus recursos para as universidades, ao passo que $20 \%$ dos professores do ensino fundamental vivem com menos de dois salários mínimos (Tarumann, 1999).

Vale enfatizar, contudo, a existência de um projeto de lei votado no parlamento (à espera da assinatura do Presidente da República) que reserva metade das vagas nas instituições federais de ensino superior aos estudantes de origem modesta, portanto oriundos das escolas secundárias públicas. Parte da clientela do ensino universitário particular provém do ensino público secundário. Quando comparada com países de desenvolvimento econômico semelhante, a taxa de escolarização dos jovens brasileiros entre 15 e 17 anos é ainda relativamente baixa, em torno de $30 \%$ (Guimarães, 1998). Essa taxa deveria aumentar durante os próximos anos, o que significa que um importante potencial de expansão se oferece às universidades particulares que já disponibilizam $60 \%$ das vagas nas universidades brasileiras.

Seria útil, agora, extrair algumas características do modelo ocidental de educação formal para medir o quanto diverge do sistema educativo brasileiro. O modelo educativo ocidental caracteriza-se especificamente por:

- Um consenso sobre o caráter eminentemente público da educação básica;

- a existência de uma forte rede de ensino particular, freqüentemente vinculada a considerações religiosas ou regionais (por exemplo, a Bretanha, na França, ou a Espanha);

- há, freqüentemente, acordos-quadros entre o ensino particular e o Estado que, em certos casos, paga os salários dos docentes, 
mas, em contrapartida, exerce um controle estreito sobre o currículo e as condições de contratação do pessoal docente;

- a diferença em matéria de despesas por aluno entre público e particular é mínima;

- a reprodução das elites não é exclusivamente da alçada da educação básica privada;

- o ensino privado universitário acolhe geralmente poucos estudantes;

- a vague neoliberal não parece ter seriamente ameaçado a prevalência do ensino público na educação básica.

Lembraremos, ainda, que certos autores estimam que o modelo educativo ocidental está também a caminho de uma fragmentação crescente, escondida na França (Careil, 1998) ou muito mais flagrante nos EUA (Kozol, 1991). Essa fragmentação baseia-se menos na dualidade público-particular do que nas disparidades dentro da própria rede pública. O mito da escola pública unitária é assim desvendado pelas conseqüências da segregação residencial sobre a escola pública.

\section{Os pilares do sistema de redes}

A fragmentação do sistema educativo brasileiro é alimentada por três fenômenos maiores: a privatização neoliberal, a descentralização e o pacto das elites.

\section{a) A privatização neoliberal}

Os anos 90 foram marcados, no Brasil, por um clima de perplexidade e de aflição geral no que diz respeito à educação. Os governos Collor e Cardoso, de orientação neoliberal, caracterizaram-se por uma política educativa incoerente, combinando um "discurso sobre a importância da educação" e um "descompromisso do Estado" no setor, com um papel crescente da iniciativa privada e das organizações não-governamentais (ONGs) (Saviani, 1996).

Como observa Frigotto (1996), a tese central do neoliberalismo é de que o setor público (o Estado) é responsável pela crise, pelos privilégios e pela ineficiência. $O$ mercado e o setor privado são sinônimos de eficiência, de qualidade e de eqüidade. A solução torna-se, então, o Es- 
tado mínimo e a necessidade de questionar todas as conquistas sociais, como a estabilidade de emprego, o direito à saúde, à educação e aos transportes públicos. O Estado deve ser reduzido a uma proporção mínima, apenas necessária para a reprodução do capital.

No plano educativo, o neoliberalismo traduz-se pela idéia central do mercado como mecanismo de regulação. O Estado deveria fornecer a cada família tíquetes (vouchers) que lhe possibilitem comprar no mercado livre o serviço educativo que Ihe convém. Por outro lado, muitas empresas privadas apadrinham ("adotam") escolas públicas. A filantropia da parceria encontra-se assim elevada ao mesmo patamar que a política educativa do Estado (Frigotto, 1996).

O surgimento de numerosas ONGs, que disputam os fundos públicos e privados, tem um duplo efeito perverso. Essas ONGs de novo tipo (com fins exclusivamente lucrativos) comprometem o trabalho antigo das ONGs tradicionais, efetivamente envolvidas junto às populações socialmente desfavorecidas. Além do mais, cria-se a ilusão de que as ONGs constituem uma alternativa democrática local ao descaso do Estado e ao seu descompromisso social (Frigotto, 1996).

Liberados da função reguladora do Estado, os consumidores da educação correm o risco de descobrir tardiamente que a mão invisível do mercado não pode ser culpada pelos defeitos e fracassos da privatização, simplesmente, porque ela não pode ser localizada. Os espaços públicos democráticos que a podem denunciar não existem e não podem ser acionados por falta de mobilização popular suficiente.

Quando as noções de qualidade (de falta de qualidade, no caso da escola pública!), e até de qualidade total substituem os conceitos de desigualdade estrutural e de injustiça social no debate, a reprodução das desigualdades sociais por um sistema educativo de várias redes encontra-se amplamente facilitada e praticamente legitimada. A falta de qualidade do ensino público é apresentada de maneira recorrente para explicar as dificuldades da rede pública brasileira. Ora, a falta de qualidade de uma organização é freqüentemente explicada pela falta de qualidade de seus atores: alunos, docentes, administradores e pais. As faIhas são assim atribuídas às inaptidões individuais. As determinantes sociais e culturais são completamente evacuadas.

Quanto ao papel da escola na reprodução das desigualdades sociais, podemos distinguir, a partir de 1934, três momentos na história escolar brasileira. O primeiro (1934-64) corresponde ao período histórico em que a reprodução social dispensa amplamente a escola, uma vez que o 
"eleito" podia herdar seu capital industrial ou agrícola sem recorrer a diplomas escolares. As estratégias desenvolvidas eram antes centradas na família ou nas alianças matrimoniais. O controle da produção do café e do leite garantia a hegemonia das elites do Sudeste sobre o país inteiro. $\mathrm{O}$ capital escolar como estratégia suplementar de reforço do poder das classes dominantes era relativamente secundário. $O$ verdadeiro ator do jogo escolar durante esse primeiro momento era o Estado, preocupado nos anos 40, 50 e 60 com a contratação, por meio da escolarização de massa, de sua base administrativa (burocrática) e de uma mão-de-obra melhor qualificada para seu modelo de desenvolvimento baseado na substituição da importação. Assim, o lançamento da campanha nacional de educação rural do governo Getúlio Vargas visava elevar o nível econômico das regiões rurais por meio das técnicas modernas de produção.

O segundo momento corresponde à ditadura militar (1964-1985) e pode ser considerado como um período em que o debate educativo foi reduzido a um agenciamento tecnicista. Foi o triunfo da pedagogia como técnica de transmissão de conhecimentos neutros, social e politicamente. O regime militar instituiu uma contribuição chamada de salário-educação nas empresas com mais de 100 funcionários, o que permitia a compra de vagas no ensino particular (Zibas, 1997). Esse segundo momento parece-nos extremamente relevante, na medida em que pôs um termo às lutas políticas e sociais das classes populares e preparou o terceiro momento (neoliberal) ao despolitizar o debate educativo.

O terceiro momento (depois de 1985) marca um retorno do debate democrático sobre a educação, depois do congelamento dos espíritos durante a ditadura militar. O capital escolar começa a desempenhar um papel cada vez mais importante. As famílias e os grupos sociais dominantes implementam então estratégias múltiplas para garantir para si o domínio do capital escolar, especificamente por meio da privatização e da descentralização do ensino.

O desmantelamento da educação pública e o desenvolvimento do ensino particular tornam-se, assim, ferramentas preponderantes. Como, por outro lado, o domínio do capital econômico é quase definitivamente garantido para certos grupos hegemônicos, o jogo torna-se então principalmente escolar, mais especificamente para os membros das classes médias altas. Encontrar uma vaga na rede escolar particular é a única possibilidade para esperar conseguir uma mobilidade social. Zibas (1997) ressalta que os antigos argumentos éticos e filosóficos sobre as pretensas vantagens da escola particular (direito da família, pluralidade 
ideológica e religiosa) se transformaram em uma racionalidade de tipo administrativo e econômico.

O funcionamento da tributação fiscal direta sobre o ensino particular e a compra maciça de manuais escolares das editoras privadas é uma fonte de desigualdade social suplementar, ao invés de servir para mitigar as disparidades sociais e regionais existentes e de favorecer a igualdade de chances por meio da redistribuição das rendas. Se nada vier modificar o curso das coisas no sistema educativo brasileiro, será grande o risco de ver essas desigualdades aprofundarem-se ainda mais. Além disso, a estratégia adotada pelo Governo atual é a de dar um lugar importante ao marketing, de modo a defender suas realizações no campo educativo. Entre suas primeiras ações de grande visibilidade, o presidente Cardoso foi à televisão para falar da educação (Garcia, 1999).

\section{b) A descentralização}

A progressiva descentralização do ensino fundamental possibilitada pelo retorno à democracia, em 1985, não foi acompanhada por um dispositivo de apoios financeiro, técnico e pedagógico suficientes, nem por uma garantia acerca da qualidade do ensino ministrado nas escolas municipais. Esse processo de descentralização da educação constituiuse, no Brasil, em um mecanismo vertical e pouco democrático. O Estado Federal delegou aos estados, às municipalidades, às ONGs e às comunidades locais a gestão da educação pública básica sem implementar um planejamento que permitiria um financiamento adequado em todas as regiões do país.

No entanto, no plano legislativo, o artigo 212 da Constituição $\mathrm{Fe}$ deral estipula que pelo menos $18 \%$ das receitas fiscais federais e $25 \%$ das receitas dos estados e das municipalidades sejam alocadas à manutenção e ao desenvolvimento do ensino (Weber, 1998).

O governo central parece também ignorar a tradição clientelista e o fisiologismo que caracterizam a classe política do interior do país, fortemente controlada pelas forças retrógradas e populistas. Ex-sociólogo marxista, o atual presidente Cardoso escolheu aliar-se, para governar, à ala mais retrógrada da direita brasileira, muito bem implantada no Nordeste. Garcia (1999) estima que o governo federal abandonou a forma tradicional de colaboração com os estados e as municipalidades para adotar uma postura tecnocrática agressiva que pode prejudicar a educação no país inteiro. 
Mesmo no contexto de um país desenvolvido como a França, certos especialistas levantam-se para denunciar as conseqüências da descentralização sobre o agravamento das desigualdades educativas:

Quando as quantias tradicionalmente pagas pelas municipalidades tornam-se cada vez menos suficientes para fazer funcionar, no dia a dia, as escolas que a gente gostaria de ver ao mesmo tempo "abertas" e bem equipadas, os professores são obrigados, mais ainda que no passado, a recorrer a novas formas de financiamento e fazem cada vez mais apelo a seus pais. (Careil, 1998)

A riqueza das atividades pedagógicas oferecidas aos alunos torna-se ainda mais diretamente vinculada às rendas de seus pais.

Segundo Watkins (1999), o Brasil possui atualmente o sistema de financiamento da educação básica mais descentralizado da região latino-americana, sem progresso notável em matéria de educação pública. 33 Estados e mais de 45 mil municipalidades compartilham com o governo federal a responsabilidade do financiamento da educação básica. Nas zonas rurais do Nordeste, a média anual das despesas por aluno das escolas municipais é de US\$50, ao passo que as despesas nas escolas que dependem dos Estados (situadas principalmente em áreas urbanas) chegam a US\$300. A disparidade entre as escolas municipais rurais do Nordeste e as escolas dos Estados do Sudeste é ainda maior, uma vez que as despesas por alunos são, em certos casos, 20 vezes superiores nas últimas

Uma das razões dessas enormes disparidades em matéria de financiamento da educação básica no Brasil provém do fato que a descentralização reforça a desigualdade entre estados, comunidades e regiões. Os estados recebem metade dos impostos, no Brasil, principalmente graças aos impostos sobre circulação de mercadoria. Logicamente, as regiões e os estados economicamente desenvolvidos têm rendas mais importantes. As rendas são assim inversamente proporcionais às necessidades da população. As despesas municipais são principalmente garantidas por repasses federais e certas taxas locais. Embora exista, no plano federal, um mecanismo de solidariedade fiscal, ele permanece ainda embrionário. Além do mais, a pressão exercida pelo Fundo Monetário Internacional sobre as finanças federais contribui para tornar ainda mais precário o financiamento da educação. Assim, Watkins (1999) relata que, em 1996, um fundo de estabilização fiscal foi criado para reduzir o déficit nacional. Perto de um quinto das rendas do governo é, hoje em dia, automaticamente repassado para esse 
fundo. Parte desse ajuste provém do orçamento federal da educação, o que reduziu o repasse às municipalidades em $18 \%$.

\section{c) O pacto das elites}

Ao analisar a formação dos economistas brasileiros, Loureiro (1995) mostrou que as elites brasileiras constituem sua identidade e obtêm sua legitimação não pela representação democrática ou pelo jogo dos partidos, mas por suas competências técnica e científica. Embora a fragilidade dos partidos políticos e a hipertrofia do poder executivo estejam na base dessa situação hegemônica dos economistas entre as elites dirigentes, essa situação é, também, o resultado de um trabalho coletivo, realizado sobre várias décadas, no próprio cerne dos meios intelectuais e universitários. É esse trabalho que produziu a crença total na competência dos economistas como atores políticos, mais especificamente no campo da educação.

A fragmentação do sistema educativo em redes de várias velocidades consolida-se pela existência de um pacto implícito e explícito das elites que permite evitar toda polarização do debate educativo entre defensores do ensino público e os que apoiam o ensino particular.

No mundo, a mobilização sindical e o engajamento tradicional de uma parcela da classe média leiga em prol da escola pública impediram que a onda neoliberal triunfante (Reagan nos EUA e Tatcher na Grã-Bretanha) degradasse profundamente ou privatizasse o sistema educativo público nos países desenvolvidos. Até os tíquetes educativos não tiveram o sucesso esperado. No Brasil, as categorias que podem contestar a privatização rasteira do ensino e a degradação do ensino público (como os docentes de escolas públicas, os sindicalistas e as elites progressistas) são elas próprias imobilizadas pela incoerência de sua inclinação em escolarizar seus filhos no ensino particular, embora pretendam defender o ensino público.

A outra dificuldade perversa está vinculada ao debate envenenado trazido pelo Banco Mundial quanto à pretensa necessidade absoluta de reorientar os fundos públicos do ensino superior para a educação básica. Ora, as universidades públicas representam talvez o último lugar em que se conduz uma defesa sincera da educação pública. Além do mais, as universidades públicas brasileiras contribuem para o desenvolvimento tecnológico do país, que corre o risco de depender completamente, nesse campo, das multinacionais estrangeiras, caso o sistema universitário público venha a ser desmantelado. 
No mesmo tempo, o pacto das elites parece seduzir certos universitários. Especialistas da educação que não podem ser taxados de conservadores estimam que o debate não deve mais ser colocado em termo de dualidade entre ensino público e particular. Assim, Gadotti (1992), ex-colaborador de Paulo Freire, considera um erro, curiosamente, opor ensino público e ensino particular. Ele pensa que todas as famílias ideológicas estão, no Brasil, defendendo um ou o outro. É verdade que a igreja católica, por exemplo, que dirige uma rede privada com clientela essencialmente elitista, não hesita em financiar escolas comunitárias para os alunos desfavorecidos. A Conferência Nacional dos Bispos do Brasil (CNBB) até defendeu, em certos períodos, a escola pública (Cury, 1992). Mesmo assim, está claro que o ensino particular beneficia apenas uma pequena minoria da população.

Num artigo recente, intitulado "Ensino particular ou público: uma falsa questão?", Moura Castro (1997) ilustra perfeitamente a colusão de certos especialistas da educação com as orientações neoliberais do governo atual. Assim, este autor felicita-se que as famílias de melhores condições econômicas retirem seus filhos no final do ensino primário público para colocá-los no ensino particular, pois esse procedimento aumenta, segundo ele, sua "competitividade" para o vestibular. O autor afirma que o ensino particular é $50 \%$ mais eficiente para levar os alunos ao final da segunda fase. No entanto, ambas as redes (pública e particular) diferem não apenas no plano do custo por aluno, como mencionamos acima, mas também no plano da origem social de seus públicos respectivos.

Continuando no mesmo registro, o autor pretende que o ensino particular é mais eficiente na utilização dos recursos disponíveis. Embora seja muito provável, é preciso lembrar que os custos mensais de escolaridade por aluno numa escola particular ultrapassam freqüentemente as despesas anuais por aluno nas escolas públicas (sem mesmo levar em conta as despesas anexas das famílias abastadas: clubes esportivos, aulas particulares, equipamento em softwares educativos, entre outros).

A ineficiência do sistema público comparado à eficiência do privado é apresentada sem nenhuma referência aos recursos disponíveis dentro de cada rede. Além do mais, os recursos necessários (tíquetes) para aumentar a frequentação do ensino particular não podem resultar de um repasse de fundos públicos, simplesmente porque estes não existem em quantidade suficiente. O sistema dos tíquetes, bajulado pela literatura neoliberal, não fez suas provas em larga escala em nenhum país do mundo. 
Na seqüência, Moura Castro (1997) pretende que o ensino particular ocupe os espaços deixados pelo Estado:

Quando o Estado não chega à periferia, o privado responde abrindo escolas. Quando a qualidade do ensino público deixa a desejar, o privado oferece escolas de melhor qualidade. Quando não há vagas no ensino público, o privado encarrega-se oferecê-las.

Se acreditarmos em Moura Castro, os empresários privados da educação são verdadeiros filantropos!

$\mathrm{Na}$ verdade, o autor entra em contradição com o começo do seu artigo, onde relata os números do Ministério da Educação, os quais mostram claramente que as regiões economicamente mais desenvolvidas do Brasil comportam a maior proporção de alunos no ensino privado. Por outro lado, Zibas (1995) demostrou que o ensino particular não mostra a menor preocupação para com a qualidade quando tem uma clientela de alunos adultos/trabalhadores nos seus cursos noturnos. A qualidade não é um dado estrutural do ensino particular no Brasil.

Para rematar sua apologia do ensino particular, Moura Castro (1997) estima que este oferece mais "diversidade", que pode ser "autogovernado, economizando energias administrativas, do poder publico"! Funcionário de um banco internacional, o autor parece confundir uma análise crítica do sistema educativo brasileiro com as orientações ideológicas das instituições financeiras internacionais (inclusive a instituição em que trabalha).

O Banco Mundial recomenda explicitamente que o Brasil conduza uma política de privatização do ensino. Isso deveria incluir, segundo o Banco, um financiamento público para os empresários privados da educação, de modo que construam escolas nas zonas desfavorecidas (World Bank, 1989). A introdução de grandes projetos como os do Banco Mundial, no Nordeste do país, facilita a difusão da ideologia da racionalidade econômica que o debate educativo coloca nos seguintes termos:

- O país não precisa de mais recursos para a educação;

- há vagas para todos os alunos na escola, o que falta fazer é meIhorar a execução;

- o problema do ensino é a repetência e não a permanência na escola (abandono) (Garcia, 1999). 
Para concluir essa parcela consagrada à análise dos pilares subjacentes à fragmentação do sistema educativo brasileiro em várias redes, parece-nos relevante assinalar que, provavelmente, nunca insistir-se-á o suficiente sobre as conseqüências da instauração do regime militar para a desmobilização das classes médias e populares com relação à defesa da escola pública. Quando se observa também a solidez do pacto das elites no plano local, mas também internacional, parece muito difícil romper a lógica das redes e pôr um termo ao clima atual de desmobilização no que diz respeito ao ensino público. No campo da política educativa, podemos observar duas orientações: a primeira tem uma confiança absoluta no mercado como agente de regulação social e a segunda contempla o papel central do Estado na luta contra as desigualdades (Zibas, 1997). No Brasil, o triunfo da primeira orientação torna praticamente impossível toda reforma estrutural do sistema educativo.

O paradoxo no qual se encontra a reforma educativa brasileira é perfeitamente descrito por Benevides (1996, p. 22):

Pensamos numa educação avançando rumo ao desenvolvimento e à construção de uma verdadeira cidadania, mas permanecemos prisioneiros dos modelos culturais do parasitismo e da dependência colonial. Debatemos soluções convencionais que estorvam todo avanço. Esse paradoxo encontra sua explicação não na organização escolar enquanto tal, mas na cultura e na mentalidade conservadora de uma sociedade de tipo oligárquico.

\section{Altemativas possíveis}

Apesar de uma conjuntura intelectual difícil para a defesa da escola pública, um formidável potencial de resistência existe tanto no plano acadêmico quanto no popular. Assim, houve mobilização quando das discussões em torno da promulgação da nova Lei de Diretrizes e Bases da Educação Nacional. O fórum de defesa da escola pública, reunindo mais de 15 organizações nacionais, apoiou fortemente o direito a uma educação de qualidade para todos (Portela de Oliveira, 1996).

No plano acadêmico, diversos trabalhos têm analisado a estrutura de desigualdade do sistema educativo brasileiro e a contribuição da escola para a reprodução das desigualdades sociais. Aos trabaIhos mais antigos de Cunha (1985), Curry (1989) e Saviani (1992) acrescentaram-se os de Gentili (1994), Frigotto (1995) e Zibas (1995). 
Não é exagero afirmar que esses trabalhos merecem ser conhecidos e discutidos tanto nos países em desenvolvimento quanto no mundo industrializado.

Cury \& Nogueira (1989) denunciam a mercantilização do ensino e a privatização do Estado que a tornou possível. Eles lembram que a escola é também um produto de lutas sociais. Nesse sentido, a rede pública de ensino teria provavelmente uma outra configuração dentro de uma nova ordem política e social. Os recursos públicos para a rede pública significam a republicação de um Estado que, ao privatizar-se, deixou o espaço aberto aos empresários da educação para que ocupem sua "face pública". Além dessa crítica, Cury \& Nogueira (1989) conclamam uma política educativa em que o Estado não será mais um lugar de poder dos grupos hegemônicos da sociedade. A reorientação da política educativa do Estado será também o indício que permitirá medir a participação dos grupos subalternos da cidadania.

Ao analisar o plano decenal de educação para todos (1993-2003), Carvalho Mazzeu (1995) estima que a ancoragem pedagógica desse plano continua tecnicista, com as seguintes características:

- Ênfase sobre a produtividade e a eficiência da escola;

- prioridade para o estabelecimento de objetivos educativos nacionais em termo das competências (habilidades) que devem ser dominadas por alunos e docentes;

- ênfase sobre os recursos materiais, mais particularmente sobre as técnicas de educação a distância como uma solução contra a baixa de "qualidade do ensino" e como uma opção para a formação dos professores (análise do tipo custos-benefícios);

- ausência de uma discussão de fundo sobre a função política da escola ou sobre seu papel na formação do cidadão.

Como pano de fundo, percebemos a persistência do mito de uma sociedade homogênea e de uma neutralidade política da educação. Nenhuma vontade de oferecer uma educação de nível comparável nas redes pública e particular foi encontrada.

Mesmo os programas que supostamente melhoram o ensino público não escapam à mercantilização. Assim, o Governo lançou, a partir de 1986, diversos programas nacionais de alimentação escolar (PNAE), do livro escolar (PNLD) e do material escolar (PNME). O PNLD registrou, entre 1984 e 1985, um crescimento de 74\%. Em 1987, 55 milhões de li- 
vros didáticos foram distribuídos, o que corresponde a aproximadamente 3 livros por aluno do ensino público (Ferreira, 1995).

Apesar de algumas inovações interessantes como, por exemplo, a possibilidade dos docentes escolherem numa lista de manuais escolares fornecida pelas editoras, no início de cada ano escolar, esse programa que supostamente melhora a qualidade do ensino público básico serviu, na verdade, para financiar os interesses e as necessidades de algumas editoras privadas. Em 1987, 5 grandes editoras dominavam $85 \%$ de um mercado de mais de 50 milhões de livros, deixando apenas $15 \%$ para cerca de quarenta pequenas editoras.

Os interesses mercantis são enormes no mercado do livro escolar controlado pelas editoras de São Paulo. Em razão de prováveis pressões econômicas das editoras locais de manuais escolares, o Governador do Rio de Janeiro lançou, em Julho 1999, uma campanha contra a "paulistização" do ensino, ao afirmar que os alunos do Rio de Janeiro deviam utilizar livros editados em seu estado (Martins, 1999). O mercado do livro didático das escolas públicas é o cerne de interesses privados monopólicos que prevalecem amplamente sobre as considerações pedagógicas. Lembremos que, desde 1930, o crescimento do público escolar vem constituindo um alicerce sólido às tentativas de construção do mercado interno do livro no Brasil (Afrânio, 1993).

Segundo Ferreira (1995), a nova república brasileira pode ser considerada como um período de transição dentro da reforma conservadora. Sua trajetória corresponde a uma conciliação pelo alto com uma ampliação do circuito elitista e uma liberação do controle do poder sem que os tradicionais excluídos sejam verdadeiramente integrados como atores legítimos nas decisões. Trata-se de "uma mudança de tutela" com a participação no acesso aos bens de consumo, mas uma exclusão na tomada de decisão e no controle da vida política.

Embora reconheça, no plano do discurso, que o pleno acesso à cidadania não é possível sem resolver o problema de acesso à, de permanência na e de finalização da escolaridade dos mais excluídos, o Estado brasileiro não parece capaz de operar as mudanças estruturais necessárias para esta evolução.

No que diz respeito ao debate pedagógico interno, notamos que, no Brasil, apesar das repercussões internacionais de sua obra, Freire não exerce uma influência importante nas reformas da educação formal. Além disso, parece-nos necessário deslocar o debate educativo de uma psicopedagogia onipresente, dominada essencialmente pelas heranças 
de Piaget e Vigotski, rumo à sociologia da educação e à crítica social do neoliberalismo. Não subestimamos a importância da psicopedagogia na compreensão dos fenômenos educativos, mas acreditamos que, via de regra, ela não leva em conta os interesses políticos e contextuais do sistema educativo. No entanto, não se pode refletir sobre as reformas curriculares num Estado brasileiro, no momento, sem uma análise aprofundada e crítica das relações entre ensino público e ensino privado. Uma análise das relações entre reforma educativa e mudança social é também primordial. Nenhuma reforma educativa poderia funcionar num sistema de várias velocidades estruturado em função do interesse exclusivo das classes dominantes.

Cabe acrescentar que o movimento das escolas comunitárias - que surgiram no Norte e no Nordeste do Brasil durante os anos 70 , em razão da insuficiência do setor público e da falta de acesso à educação privada por parte dos pobres - é portador de esperanças reais. No início dos anos 90, as associações dos educadores das escolas comunitárias surgiram como uma importante força política nos movimentos populares brasileiros. Apoiado por diversas ONGs, entre as quais está o Centro de Educação Popular, esse movimento mobilizou-se para obter o reconhecimento legal e o suporte financeiro para as escolas comunitárias. Em 1998, um emenda constitucional reconhecia a existência legal dessas escolas.

A experiência educativa do Movimento dos Sem Terra (MST) merece também uma analisa aprofundada. Milhares de alunos são atualmente escolarizados nas escolas administradas pelo movimento. Um primeiro encontro nacional dos educadores do MST foi recentemente organizado em Brasília.

Por fim, as experiências das municipalidades progressistas como a de Porto Alegre têm o mérito de mostrar que existem alternativas práticas e viáveis à gestão neoliberal da educação.

\section{Conclusão}

Neste artigo, tentamos demonstrar que o sistema educativo brasileiro atual não é uma fotocópia conforme do modelo ocidental ou europeu, uma vez que diverge deste último sob muitos aspectos. O ganho de potência do setor privado (em todos os níveis do ensino), único habilitado para reproduzir as elites, pode ser também constatado em outras regiões do Sul. Seria útil, portanto, refletir sobre a possibilidade de uma terceira via entre escola pública em crise e escola particular a serviço de 
uma minoria de privilegiados. Essa terceira via, que Freire (1991) chamou de escola pública popular e Antonioli (1993) de escola de base, deve ser a prioridade para os pedagogos progressistas.

A seguir, devemos examinar as condições necessárias para atacar as desigualdades educativas estruturais. Isso só pode acontecer rompendo com a lógica das redes de várias velocidades. Em outras palavras, meIhorando a estrutura e os apoios políticos do setor público (aumentando a velocidade!) para torná-los comparáveis aos da rede particular. A questão-chave é a insuficiência dos recursos para a educação pública. Está certo que propor o aumento das despesas para a educação pública pode parecer provocador para certos economistas, na medida em que o período atual é caracterizado pela adoção, de modo religioso, de restrições orçamentárias. Ora, se observarmos que o governo federal gastou vários biIhões de dólares para sustentar bancos privados ou a paridade da moeda nacional com o dólar, podemos nos surpreender com o fato dele não encontrar os financiamentos necessários para a educação pública.

Os financiamentos apropriados devem ser encontrados essencialmente no plano interno, na medida em que os financiamentos bilaterais ou multilaterais para a educação básica, como os do Banco Mundial, são infelizmente mais orientados para realizações materiais visíveis do que para reformas estruturais.

Do mesmo modo, a suspensão do financiamento público (direto e indireto) das empresas privadas (escolas e editoras) é necessária. Uma reflexão nacional sobre os manuais escolares é urgente. De fato, o dinheiro público ganho pelos empresários privados do setor da edição é uma situação provocadora.

Além disso, uma maior mobilização do corpo docente e dos especialistas em ciências da educação é também imprescindível. Essa mobilização passa pela necessidade de denunciar o mito do mercado livre dos serviços educativos. Com efeito, esse mercado não passa de uma das facetas da distribuição injusta das rendas, uma vez que $15 \%$ dos brasileiros controlam $90 \%$ da riqueza criada no país (da Silva, 1998). $\mathrm{Na}$ medida em que cada rede se dirige a consumidores diferentes, o sistema educativo brasileiro não constitui um mercado livre, nem concorrencial. Apesar da oposição ferrenha do Banco Mundial, um aumento dos salários dos docentes da educação pública é indispensável para sua remobilização em prol da educação pública. Os docentes da rede pública podem se mobilizar profissionalmente, mas também no plano pessoal, e tornar a escolarizar seus filhos no ensino público. A relação de força 
a favor da educação pública poderá então mudar de modo durável, na medida em que os docentes se sentirem ainda mais atingidos por sua degradação.

A fragmentação do sistema educativo brasileiro em redes de várias velocidades é uma conseqüência do fracasso do planejamento escolar. Contudo, não é pertinente deixar a mão invisível do mercado substituir-se aos poderes públicos. O Estado deve, portanto, ser o verdadeiro regulador e garante do conjunto do sistema educativo. Assim, é vão empreender uma reforma da rede pública sem fixar novas regras do jogo para o privado ou sem uma reflexão sobre a educação informal e a formação profissional. Os Estados, as regiões e os indivíduos favorecidos devem participar de uma maneira ou de outra da educação dos mais pobres. Essa solidariedade é uma condição necessária para começar a se falar em cidadania. Mais do que nunca, o Estado deve estar presente na organização do sistema de educação. Não se trata de implementar mais dirigismo burocrático, mas de balizar uma verdadeira solidariedade cidadã.

O discurso neoliberal atual sobre a educação é elitista. Ele justifica as desigualdades sociais e o triunfo dos mais fortes. Ele culpa os mais pobres e os docentes. Ele legitima o poder dos administradores, dos tecnocratas e dos recursos materiais (manuais escolares). Ele considera o mercado como a única racionalidade possível. Entretanto, o mercado não é um princípio de regulação social. Ele nunca o foi e nunca o será. Claro, o mercado da educação cria, hoje em dia, muitas pessoas ricas no Brasil. É eficiente para organizar o consumo dos bens e dos serviços educativos, para criar benefícios, sobretudo, mas as sociedades que lhe dão livre curso, sem nenhuma regulação, são por definição desigualitárias e não democráticas. O sistema educativo brasileiro não é regido pela competição, mas pelo monopólio exercido pelas escolas particulares sobre a qualidade. É de se temer que a situação brasileira tenha um efeito de lupa. Vê-se nela mais cedo, e de modo mais flagrante e intenso, as transformações que estão minando os sistemas educativos dos países do Sul e do Norte.

Recebido para publicação em 15 de janeiro de 2000.

\section{StruCtuRAL SCHOOLING INEQUALITIES IN BRAZIL: BETWEEN STATE, PRIVATIZATION AND DESCENTRALIZATION}

ABSTRACT: In Brazil, more than in any other Southern country, school is an unequally distributed social product. Access to it depends not only on such distinctive standards as socioeconomic position, sex, ethnicity, location of residence etc., but also on the type of 
network attended (public, private). This paper analyses the historical and progressive constitution of a multispeed schooling network. The republican political speech, which highlights the egalitarian and homogenizing function of school, has been gradually losing its substance. The heterogeneity resulting from the current fragmentation of the Brazilian schooling system into various networks reproduces, magnifying them, all social inequities and lastingly endangers the social and economical development of this country.

Key words: Brazil, social inequalities, public education, particular education

\section{Referências bibliográficas}

AFRÂNIO, G. Les intellectuels et la conscience nationale au Brésil. Actes de Recherches en Sciences Sociales, 98, 1993, p. 20-33.

AKKARI, A. (1999). The construction of mass schooling in Brazil: A two-tiered educational system. Education and Society, vol. 17 (1), 1999, p. 37-52.

ANTONIOLI, A. Le droit d'apprendre. Une école pour tous en Afrique. Paris: L'Harmattan, 1993.

AZEVEDO, F. et al. O manifesto dos pioneiros da educação nova. São Paulo: Nacional, 1932.

BENEVIDES, F.C. Educação em tempo de reforma. Revista Adusp, ago. 1996, p. 21-23.

CAREIL, Y. De l'école publique à l'école libérale. Sociologie d'un changement. Rennes: Presses Universitaires de Rennes, 1998.

CUNHA, L.A. Limites da escola particular e a democratização do ensino. In: CUNHA, L.A. (ed.). Escola publica, escola particular e a democratização do ensino. São Paulo: Cortez, 1985, p. 119-130.

CURY, C.R. A educação e a nova ordem constitucional. Ande - Revista da Associação Nacional de Educação, 14, ano XVIII, 1989, p. 5-11.

. O público e o privado na educação contemporânea, Cadernos de Pesquisa, 81, 1992, p. 33-44.

FREIRE, P. A educação na cidade. São Paulo: Cortez, 1991.

FRIGOTTO, G. Educação e a crise do capitalismo real. São Paulo: Cortez, 1995.

Os delírios da razão: Crise do capital e metamorfose conceitual no campo educacional. In: GENTILI, P. (ed.) Pedagogia da exclu- 
são. Critica ao neoliberalismo em educação. Petrópolis: Vozes, 1996, p. 77-108.

GARCIA, W. Educação Brasileira: Da realidade a fantasia. Cadernos de Pesquisa, 107, 1999, p. 227-245.

GOMES DE SÁ PESTANA et al. Saeb 97: Primeiros resultados. Brasília: Instituto Nacional de Estudos e Pesquisas Educacionais, 1999.

GENTILI, P.A. \& SILVA, T.T. Neoliberalismo, qualidade total e educação. Petrópolis: Vozes, 1994.

GUIMARÃES, M.H. Avaliação do sistema educacional brasileiro. Tendências e perspectivas. Ensaio, 6(20), 1998, p. 303-364.

INEP. Censo Escolar. Sinopse Estatística 1996. Brasília: INEP, 1996.

KOZOL, Jonathan. Savage inequalities. New York: Crown Publishers, 1991.

LIBANEO, J. C. Democratização da escola publica. A pedagogia criticosocial dos conteúdos. 14ª ed. São Paulo: Edições Loyola, 1985.

LIMA, M. Lugar marcado. Projeto de lei propõe cotas nas faculdades do governo para alunos de rede publica. São Paulo, Veja, jul. 1999, p. 46-47.

LOUREIRO, M.R. L'ascension des économistes au Brésil. Actes de Recherches en Sciences Sociales, 108, 1995, p. 1-78.

MARTINS, C. Conde bloqueia a 'paulistização'. Jornal do Brasil, 15 jul. 1999, p. 19.

MEC. Desenvolvimento da Educação no Brasil. Brasília: Ministério da Educação, 1996.

MESQUIDA, P. Hegemonia Norte-Americana e Educação Protestante no Brasil. Juiz de Fora. São Bernardo do Campo: Editora da UFJF/ Editeo, 1994.

MOURA CASTRO, C. de. Ensino Privado ou público : Eis a (falsa) questão. Ensaio, 5 (17), 1997, p. 423-452.

PORTELA DE OLIVEIRA, R. LDB, uma questão emblemática na política educacional brasileira. REVISTA Adusp, Jan. 1996, p. 22-24.

SABOIA, J. Trabalho Infanto-Juvenil no Brasil dos Anos 90. Rio de Janeiro: Unicef, 1996.

SAVIANI, D. Pedagogia Histórico-crítica. Primeiras aproximações. São Paulo: Cortez, 1992. 
. Escola e Democracia. São Paulo: Cortez, 1996.

SILVA, A. R. da. A importância da educação publica para o ensino fundamental das classes trabalhadoras. Cadernos de Apoio ao Ensino UEM, 4, 1998, p. 5-42.

SIMÕES BUENO, M. S. Itinerário do descompromisso na escola pública de $2^{\circ}$ grau Paulista. Cadernos de Pesquisa, 99, 1996, p. 173-79.

TRAUMANN, T. O Paradoxo de ACM. Veja, ago. 1999, p. 46-48.

WATKINS, K. Education now: Break the cycle of Poverty. London: Oxfam, 1999.

WEBER, S. Novos padrões de financiamento e impactos na democratização do ensino. Cadernos de Pesquisa, 103, 1998, p. 5-13.

WORLD BANK. Issues in Brazilian secondary education. (Report $\mathrm{n}$. 7723BR), Latin American and Caribbean Regional Office, 1989.

ZIBAS, D. M. A escola pública e a escola privada diante das propostas de modernização do ensino médio. Tese de doutorado: USP, 1995.

. Escola pública versus Escola privada: O fim da história? Cadernos de Pesquisa, 100, 1997, p. 57-77.

\section{Anexo}

Organização do sistema educativo brasileiro

\begin{tabular}{|l|l|l|}
\hline Nível & Duração & Idade \\
\hline Educação infantil & & $0-6$ anos \\
\hline Ensino fundamental & 8 anos & $7-14$ anos \\
\hline Ensino médio & 4 anos & $15-18$ anos \\
\hline Vestibular & & \\
\hline Educação superior & & \\
\hline
\end{tabular}

Fonte: MEC (1996). 